\title{
Irritable bowel syndrome: relationship of disorders in the transit of a single solid meal to symptom patterns
}

\author{
P A CANN, N W READ, C BROWN, \\ N HOBSON, AND C D HOLDSWORTH \\ From the Clinical Research Unit, Royal Hallamshire Hospital, Sheffield
}

SUMmary The time taken for a solid meal to pass through the stomach, small intestine, and colon was measured in 61 patients with irritable bowel syndrome, subdivided according to their presenting symptoms, and in 53 healthy volunteers. Small bowel transit times were significantly shorter in patients who complained predominantly of diarrhoea $(3 \cdot 3 \pm 0 \cdot 3 v s 4 \cdot 2 \pm 0 \cdot 2 \mathrm{~h} ; \mathrm{p}=0 \cdot 01$; $\mathrm{n}=21$ ) and significantly longer in patients who complained predominantly of constipation $(5.4 \pm 0.3$ vs $4.2 \pm 0.2 \mathrm{~h} ; \mathrm{p}<0.01 ; \mathrm{n}=23)$ or pain and distension $(5.4 \pm 0.4$ vs $4.2 \pm 0.2 \mathrm{~h} ; \mathrm{p}<0.01$; $\mathrm{n}=17$ ) compared with controls. Whole gut transit times were shorter in patients who complained of diarrhoea $(35 \pm 5$ vs $53 \pm 4 \mathrm{~h} ; \mathrm{p}<0.01)$, and longer in patients with constipation $(87 \pm 13 v s 53 \pm 4$ $\mathrm{h} ; \mathrm{p}<0.05)$ compared with controls. No significant differences in gastric emptying rates were shown between any of the patient groups and normal controls. Thirty-four patients reported pain, particularly in the right iliac fossa, during the meal transit test, and in 25 of these (74\%), the onset of the pain was associated with the arrival of residues of the test meal in the caecum. Our results indicate that irritable bowel syndrome should be considered a disease of the small intestine as well as the colon.

Irritable bowel syndrome is widely regarded as a disorder of colonic motor activity, ${ }^{1-3}$ though some evidence suggests that it may encompass abnormalities in the motor activity of other parts of the gastrointestinal tract. ${ }^{4-6}$ It may be difficult to show such disorders by measuring intraluminal pressure or myoelectrical activity because of the wide range of normal motor activity and because symptoms in irritable bowel syndrome are usually related to the presence of food in the gut, while measurements of motor activity are more easy to interpret with the bowel empty. We have investigated the effects of abnormal motor activity in patients with irritable bowel syndrome by relating the time taken for a meal to pass through the stomach, small intestine, and colon to the patients' symptoms. An important advantage of this 'meal transit test' is that it does not involve the subject swallowing an intestinal tube. Intubation is poorly tolerated by irritable bowel syndrome patients and

Address for reprints: Dr P A Cann. Clinical Research Unit. Floor H. Royal Hallamshire Hospital. Sheffield S10 2JF.

Received for publication 9 August 1982 can itself slow gastric emptying and accelerate small bowel transit. $^{\text {? }}$

\section{Methods}

SUBJECTS

All the patients were referred to the gastrointestinal clinic at the Royal Hallamshire Hospital with symptoms of abdominal pain with or without bowel disturbance. Patients were only included in the study if their symptoms had persisted for at least six months and were present on at least three days per week, if there was no clinical evidence of organic gastrointestinal disease, past or present, and if a comprehensive series of screening investigations (Table 1) yielded negative results. No medication was taken during the study.

Sixty-one patients (46 women, 15 men; mean age 36 years, range 19-64 years) satisfied these criteria and were studied. In common with other series, ${ }^{389}$ patients were subdivided according to their own description of symptoms at presentation in the clinic. The subgroups were: (a) Diarrhoea group (nine women, 12 men): these patients complained predominantly of the passage of loose, frequent 
Table 1 Screening investigations

\begin{tabular}{ll}
\hline Full blood count + ESR & $\begin{array}{l}\text { Thyroid function tests } \\
\text { Plasma urea/electrolytes/ }\end{array}$ \\
$\quad$ calcium & ${ }^{*}$ Faecal fat excretion \\
Liver function tests & ${ }^{*}$ Serum folate + vitamin $B_{12}$ \\
Rectal biopsy & ${ }^{*}$ Schilling test \\
Stool microscopy + culture & ${ }^{* 14}$ C-Glycocholate breath test \\
Barium meal + follow through & ${ }^{*}$ Lactose tolerance test \\
Barium enema & acetic acid \\
\hline
\end{tabular}

* Indicates those investigations carried out only on the patients who complained of diarrhoea.

stools, often associated with urgency and abdominal pain. (b) Constipated group (21 women, two men): these patients complained predominantly of the passage of infrequent, hard stools, associated with straining and abdominal pain. (c) Pain and distension group (16 women, one man): these patients complained predominantly of abdominal pain in association with a sensation of abdominal distension. Disturbance in bowel habit was not a prominent feature, or alternated between diarrhoea and constipation.

The overall female:male ratio of $3: 1$ in our patients is in line with other reported series 8 although the preponderance of male patients in the diarrhoea group has not been reported previously.

For comparison, measurements were carried out on 53 healthy ambulant volunteers ( 26 women, 27 men; mean age 30 years, range $21-70$ years), who had no gastrointestinal discomfort or bowel disturbance, and were not taking any medication. These subjects were students and members of hospital staff and their friends.

\section{ETHICAL CONSIDERATIONS}

All volunteers and patients gave written, informed consent, for measurements of gastrointestinal transit to be carried out. All female subjects signed a document stating that they were not pregnant and would continue to take adequate contraceptive measures for the period of investigation. Approval for the protocol was granted by the Ethical Subcommittee of the Sheffield Area Health Authority (Southern District) on 2 July 1979.

\section{STUDY DESIGN}

All subjects fasted for at least nine hours before the study. Between 9 am and $10 \mathrm{am}$, they ingested a solid test meal ${ }^{10}$ (sausages, mashed potato, baked beans, and homogenised pineapple with custard). Twenty-five microcuries $(0.93 \mathrm{MBq}){ }^{99} \mathrm{Tc}$-sulphur colloid and 50 segments $(2 \mathrm{~mm} \times 3 \mathrm{~mm})$ of radio-opaque plastic tubing were incorporated in the mashed potato.
Immediately after ingestion of the meal the subject lay supine with the head resting on pillows and measurements of gastric emptying and small bowel transit time were recorded for at least six hours. Subjects were not made aware of the stage of transit of the food during the study. Any symptoms experienced during the study were recorded alongside the transit measurements. No further food or drink was taken until measurements of small bowel transit time were complete. Subjects were then allowed to return home and asked to collect the results of each bowel movement in individual polyethylene bags, labelled with the time and date, for a period of at least 72 hours after the ingestion of the test meal.

\section{GASTRIC EMPTYING}

Radioactivity over the surface of the stomach was counted every 10 minutes using a collimated crystal scintillator (Type DM1-2, Nuclear Enterprises Ltd, Edinburgh), positioned over the site of maximum radioactivity immediately after ingestion of the meal, ${ }^{10}$ and connected to a counter ratemeter (Type SR-5, Nuclear Enterprises Ltd). Corrections were made for decay of the isotope. The time taken for the count to fall to half of the initial value $\left(t_{\frac{1}{2}}\right)$ was taken as the index of gastric emptying. This method has been shown to be reproducible and unchanged by incorporating the marker in the solid and liquid phases of the meal. ${ }^{10}$ Moreover, it can yield as accurate an index of gastric emptying as methods using the gamma camera. ${ }^{11}$

\section{SMALL BOWEL TRANSIT TIME}

This was determined by measuring the time from eating the meal to the sustained increase in breath hydrogen concentration that occurred when the unabsorbed carbohydrate residues reached the colon and were fermented by colonic bacteria ${ }^{12}$ (Fig. 1). The latter was defined as a rise of at least two parts per million above basal values, which continued to rise in samples taken over the ensuing 30 minutes. Samples of end expiratory air were collected before and at 10 minute intervals after ingesting the test meal, using a modified HaldanePriestly tube. ${ }^{13}$ The concentration of hydrogen in each sample was measured with a detector incorporating a metallised membrane, gas sensitive electrode. $^{614}$

WHOLE GUT TRANSIT TIME AND STOOL WEIGHT

The results of each bowel movement during the 72 hour period immediately after ingestion of the meal were weighed and then radiographed to determine the number of plastic markers. ${ }^{15}$ The time taken to void $50 \%$ of the markers after ingestion of the test 


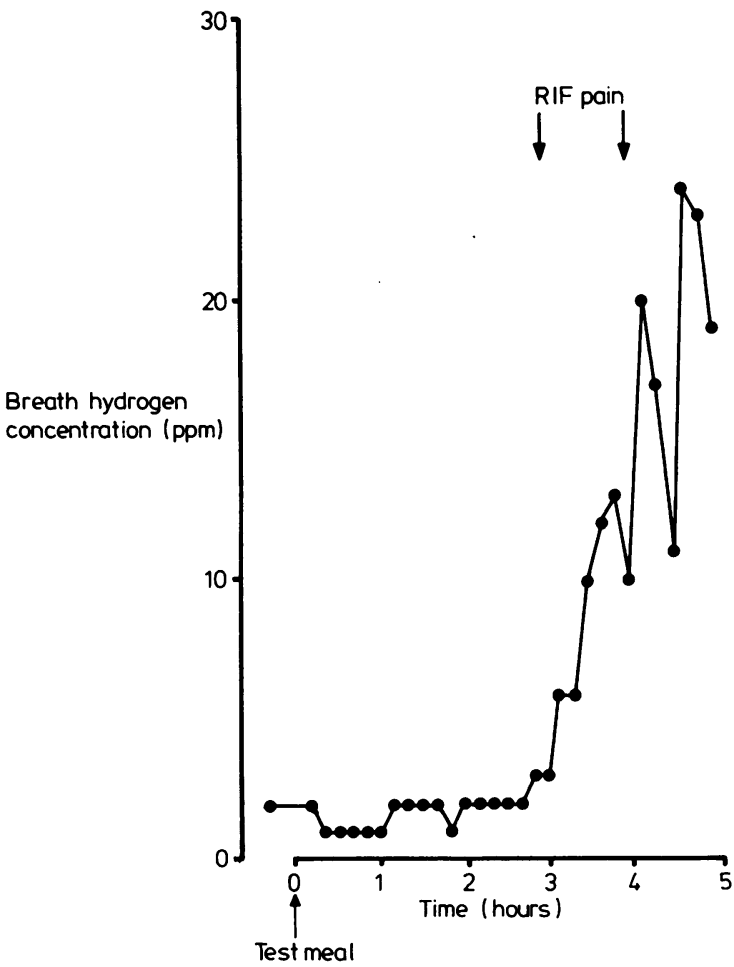

Fig. 1 Breath hydrogen profile in a typical patient, showing sustained rise in breath hydrogen excretion that occurred as unabsorbed carbohydrate residues entered the caecum. Note that patient did not complain of abdominal pain until after increase in breath hydrogen excretion.

meal provided an index of the whole gut transit time.

\section{STOOL FREQUENCY AND CONSISTENCY}

Patients recorded the time of each bowel movement on a diary card for a period of 21 days, indicating whether the stools were formed or unformed. This information was used to calculate mean daily stool frequency and the percentage of unformed stools. The meal transit study was always performed during this 21 day period.

\section{STATISTICAL ANALYSIS}

All of the data with the exception of stool consistency appeared to be normally distributed. The Wilcoxon's (unpaired) rank sum test was used to analyse differences in stool consistency between the groups. One way analysis of variance (ANOVA) was applied to the remainder of the data and unpaired $t$ tests were only used if the results of
ANOVA indicated a significant difference between the groups. In view of (a) the significant sex difference in the rates of gastric emptying and stool weights in controls (Table 2), and (b) the fact that the constipated and pain and distension groups included only two and one male patients respectively, ANOVA was applied only to female controls and female patients with respect to gastric emptying and stool weights. On this basis the two male patients with constipation and one with pain and distension were excluded. The nine male patients with diarrhoea were compared separately with male controls using an unpaired Student's $t$ test.

\section{Results}

EFFECT OF AGE AND SEX ON TRANSIT MEASUREMENTS AND STOOL WEIGHT

There were no significant correlations between age and stool weight or any of the transit measurements in the control group. The half-times for gastric emptying were slower $(p<0.05)$ and stool weights lower $(\mathrm{p}<0.05)$ in women compared with men (Table 2). No significant sex differences were found in small bowel transit time or whole gut transit time.

\section{GASTRIC EMPTYING}

There were no significant differences in gastric emptying ( $\left.t \frac{1}{2}\right)$ between controls and any of the patient subgroups (Table 3).

\section{SMALL BOWEL TRANSIT TIME}

Small bowel transit time (Fig. 2) was significantly longer in patients with constipation $(p<0.01)$ and in patients with pain and distension $(p<0 \cdot 01)$, compared with control subjects, but significantly faster than control in patients with diarrhoea $(\mathrm{p}=0.01)$.

WHOLE GUT TRANSIT TIME

Whole gut transit time was significantly longer in the constipated group compared with control subjects

Table 2 Comparison of transit measurements and stool weights in male and female control subjects

\begin{tabular}{lccl}
\hline & $\begin{array}{l}\text { Men } \\
(n=27)\end{array}$ & $\begin{array}{c}\text { Women } \\
(n=26)\end{array}$ & $p$ \\
\hline Gastric emptying half-time (h) & $1 \cdot 3 \pm 0 \cdot 1$ & $1 \cdot 6 \pm 0 \cdot 1$ & $<0 \cdot 05$ \\
Small bowel transit time (h) & $4 \cdot 0 \pm 0 \cdot 3$ & $4 \cdot 3 \pm 0 \cdot 3$ & NS \\
Whole-gut transit time (h) & $50 \pm 6$ & $55 \pm 5$ & NS \\
24 h stool weight (g) & $166 \pm 20$ & $112 \pm 12$ & $<0.05$ \\
\hline
\end{tabular}

Results are expressed as mean \pm SEM.

NS = not significant. 
Table 3 Transit measurements and stool data in normal volunteers and patients with irritable bowel syndrome

\begin{tabular}{|c|c|c|c|c|c|}
\hline & & \multirow[b]{2}{*}{ Control } & \multicolumn{3}{|c|}{ Irritable bowel syndrome } \\
\hline & & & Diarrhoea & Constipation & Pain/distension \\
\hline \multirow[t]{2}{*}{ Gastric emptying $\left(\mathrm{t} \frac{1}{2} ; \mathrm{h}\right)$} & $\mathbf{F}$ & $1 \cdot 6 \pm(0) \cdot 1$ & $1 \cdot 6+(1) \cdot 1$ & \multirow[t]{2}{*}{$1 \cdot 8 \pm 0 \cdot 2$} & \multirow[t]{2}{*}{$1.4 \pm 0.2$} \\
\hline & $\mathbf{M}$ & $1 \cdot 3 \pm() \cdot 1$ & $1 \cdot 3+(1) \cdot 2$ & & \\
\hline Small bowel transit time (h) & \multirow{6}{*}{$\begin{array}{l}\mathbf{F} \\
\mathbf{M}\end{array}$} & \multirow{6}{*}{$\begin{array}{c}4 \cdot 2 \pm 0 \cdot 2 \\
53 \pm 4 \\
112 \pm 12 \\
166 \pm 20\end{array}$} & $3 \cdot 3 \pm\left(0 \cdot 3^{*} \ddagger \S\right.$ & \multirow{4}{*}{$\begin{array}{l}5 \cdot 4 \pm 0 \cdot 3^{*} \dagger \\
87 \pm 13^{*}+ \\
61 \pm 17^{*}+\end{array}$} & \multirow{4}{*}{$\begin{array}{l}5 \cdot 4 \pm 0 \cdot 4^{*}+ \\
61 \pm 4+ \\
86 \pm 12\end{array}$} \\
\hline Whole gut transit time (50\% markers; h) & & & $35 \pm 5^{*} \pm \S$ & & \\
\hline \multirow[t]{2}{*}{ Daily stool weight (g) } & & & $128 \pm 25 \ddagger$ & & \\
\hline & & & 23()$\pm 24^{*}$ & & \\
\hline Daily stool frequency & & & $2 \cdot 3 \pm 0 \cdot 2 \ddagger \S$ & $0.9 \pm(0 \cdot 2+8$ & $1 \cdot 5 \pm 0 \cdot 2+\ddagger$ \\
\hline Percent unformed stools & & & $75 \ddagger \S$ & $18+\S$ & $48+\ddagger$ \\
\hline
\end{tabular}

Results are expressed as mean \pm SEM, and p values are calculated using Student's $t$ test for all data except percent unformed stools, which are expressed as means with p values calculated from the Wilcoxon's rank sum test (see Methods).

* Significantly different $(p<0 \cdot(05)$ from corresponding control group; +diarrhoca group; $\ddagger$ constipated group; \$pain/distension group.

$(p<0.05)$, but significantly shorter than control in patients with diarrhoea $(\mathrm{p}<0.01)$ (Table 3$)$. There was no significant difference in the results from patients with pain and distension and control subjects.

\section{HOUR STOOL WEIGHT}

Average daily stool weight was within the normal range $(50$ to $200 \mathrm{~g} / \mathrm{d}$ ) in most patients with irritable bowel syndrome. Forty-eight per cent of the diarrhoea group had stool weights exceeding 200

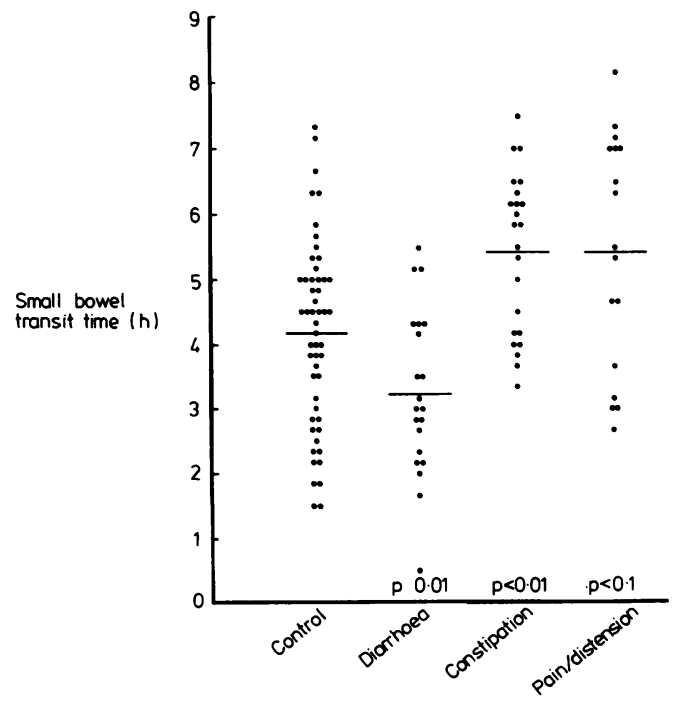

Fig. 2 Small bowel transit times in control subjects and patient subgroups. Group means are shown with probability figures indicating significance of differences from control group. g/d, compared with $5 \%$ of the constipated group and no patients in the pain and distension group $\left(p<0.001\right.$ on $\chi^{2}$ test). Conversely, 55\% of the constipated group had daily stool weights below 50 $\mathrm{g} / \mathrm{d}$, compared with $5 \%$ of the diarrhoea group and $25 \%$ of the pain and distension group $\left(\mathrm{p}<0.01\right.$ on $\chi^{2}$ test).

Average daily stool weight was lower in patients who complained of constipation than control subjects $(p<0.01)$, higher in male patients with diarrhoea than male controls $(p=0.05)$, but not significantly different from control in female patients with diarrhoea or with pain and distension (Table 3).

MEAN STOOL FREQUENCY

Patients with diarrhoea passed more frequent stools compared with patients complaining of constipation $(\mathrm{p}<0.001)$ and pain and distension $(\mathrm{p}<0.01)$ (Table 3). Mean stool frequency in the constipated group was significantly lower than in the group complaining of pain and distension $(p<0.05)$.

\section{STOOL CONSISTENCY}

Patients with diarrhoea passed a significantly higher percentage of unformed stools compared with those complaining of constipation $(\mathrm{p}<0.01)$ or pain and distension $(\mathrm{p}<0.01)$ (Table 3$)$. Patients with constipation passed a significantly lower percentage of unformed stools than those who complained of pain and distension $(\mathrm{p}<0 \cdot 01)$.

\section{COMPARISON OF TRANSIT MEASUREMENTS IN} DIARRHOEA AND CONSTIPATION BASED ON STOOL WEIGHTS

Ten patients with daily stool.weights exceeding $200 \mathrm{~g}$ were compared with 17 patients with daily stool weights below $50 \mathrm{~g}$. Small bowel transit time was significantly faster in the high stool weight group 
$(3.4 \pm 0.5$ vs $5.2 \pm 0.4 \mathrm{~h} ; \mathrm{p}<0.01)$ as was whole gut transit time $(25 \cdot 5 \pm 3.5 v s 95.5 \pm 15 \mathrm{~h} ; \mathrm{p}<0.001)$.

\section{CORRELATIONS BETWEEN TRANSIT}

MEASUREMENTS AND STOOL DATA

There were no significant correlations between the half time for gastric emptying and any of the other measurements in either patients with irritable bowel syndrome or healthy controls. There was a weak significant correlation between small bowel transit time and average daily stool weight in the irritable bowel syndrome group $(\mathrm{r}=-0.38, \mathrm{p}<0.01)$, but not in the control group $(r=0 \cdot 08)$. There were no correlations between small bowel transit time and either whole gut transit time or daily stool frequency in either group. There was an inverse curvilinear relationship between whole gut transit time and daily stool weight $\left(\log _{10}\right.$ daily stool weight vs whole gut transit time; controls: $r=-0.65$, $\mathrm{p}<0.001$; irritable bowel syndrome patients: $r=-0.63, p<0.001)$. Stool frequency was not measured in controls, but correlated inversely with whole gut transit time in irritable bowel syndrome patients $(r=-0.44, p<0.01)$.

\section{DIRECT RELATIONSHIP OF SYMPTOMS TO TRANSIT PROFILES}

None of the control subjects reported any symptoms during the study. Fifty-three patients were asked to report any symptoms they experienced during transit measurements. Thirty-four reported abdominal pain and in 25 of these $(74 \%)$ the pain was temporally associated with the sustained rise in breath hydrogen concentration, corresponding to the entry of test meal residues into the caecum (Fig. 1). In addition, five patients complained of abdominal distension, seven of borborygmi and two of an urge to defaecate concomitant with the onset of caecal filling. Moreover, one patient vomited and another complained of nausea, lightheadedness, profuse sweating and a sense of alarm when food residues entered the colon.

Figure 3 shows that pain associated with entry of food residues into the caecum was most commonly experienced in the right iliac fossa, but was also experienced at other sites throughout the abdomen.

\section{Discussion}

These studies have shown that the transit of food through the small intestine and the colon is faster than normal in irritable bowel syndrome patients, who present with diarrhoea, but slower than normal in irritable bowel syndrome patients, who present with constipation. The changes in the small bowel transit time of a meal have not been previously

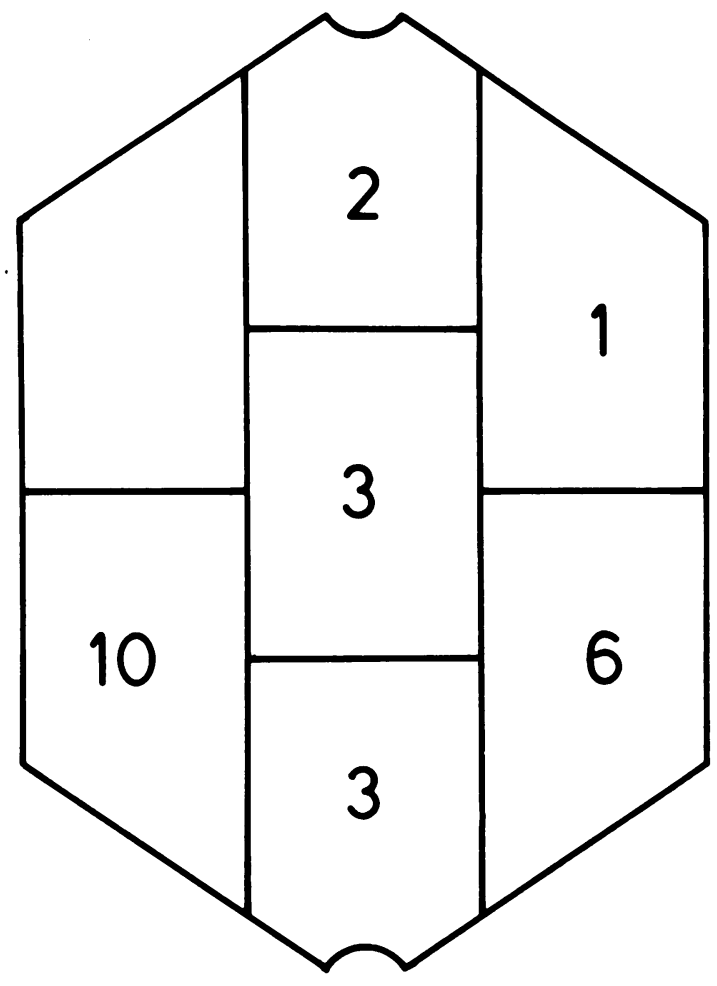

Fig. 3 Diagram shows numbers of patients who reported pain referred to each abdominal location when residues of test meal entered the colon.

reported and they emphasise that irritable bowel syndrome should be considered a disorder of the small intestine as well as the colon. ${ }^{56}$

In spite of the differences between the results from the patient subgroups and normal controls, virtually all of our patients exhibited transit measurements that were within the normal range (Fig. 2), yet continued to report abdominal symptoms and exhibit abnormal bowel habit, even during the meal transit test. This suggests that although the alteration in transit may contribute to the symptom pattern, it cannot be considered the only causative factor. It is possible that the colon in irritable bowel syndrome is less able to tolerate the effects of the usual variations in small bowel transit time, especially if this is associated with large changes in the amount of ileal effluent. The temporal relationship between the onset of abdominal pain, particularly in the right iliac fossa, and caecal filling may be explained by the apparent unusual sensitivity of the colon in patients with irritable bowel syndrome to distension ${ }^{16}$ and 
chemical stimuli. ${ }^{17}$ The presence of pain in the right iliac fossa without evidence of organic disease is a common phenomenon and may result in the removal of a normal appendix or the diagnosis of 'grumbling appendix'. ${ }^{18} 19$ The observation that pain, localised to other sites in the abdomen, is temporally related to the entry of food into the colon, is in keeping with the results of balloon distension of the colon, which can induce pain at sites which do not necessarily correspond to the anatomical source. ${ }^{20}$

Patients with irritable bowel syndrome exhibit a greater degree of life stress than normal subjects, ${ }^{21}$ and experimental stress dramatically influences colonic motor activity. ${ }^{22} \mathrm{We}$ recently found that applying a controlled psychological stress to normal volunteers significantly accelerated small bowel transit, but did not affect gastric emptying. ${ }^{23}$ This result may explain the rapid small bowel transit in patients with diarrhoea, especially as only irritable bowel syndrome patients who present with diarrhoea exhibit high anxiety scores. ${ }^{21}$ The delayed small bowel transit time in constipation is less easy to explain, but could result from a reflex inhibition of small intestinal motility, induced by colonic distension (Youle and Read, unpublished observations), or could be because of a disturbance in humoral or nervous control, shared by both the small and large intestine.

The findings reported in this paper may help to put the management of irritable bowel syndrome on a more rational footing. We are currently investigating how patients with irritable bowel syndrome respond to pharmacological agents which accelerate or retard small bowel transit. The presence of unabsorbable carbohydrate in food is known to accelerate transit through the small bowe ${ }^{10}$ as well as the colon, ${ }^{24}$ and whether patients with irritable bowel syndrome feel better or worse after ingesting unabsorbable carbohydrate may depend on whether they have abnormally rapid or slow transit times.

We are grateful to Dr D C Barber and Miss S Sheriff of the Department of Medical Physics, University of Sheffield, for advice, use of facilities and loan of equipment, and to the Department of Community Medicine, University of Sheffield, for guidance with statistical analysis. The study was supported by a project grant from the Medical Research Council. Dr Cann was funded by Janssen Pharmaceuticals (UK), Marlow, Bucks.

\section{References}

1 Snape WJ, Carlson GM, Matarazzo SA, Cohen S. Evidence that abnormal myoelectric activity produces colonic motor dysfunction in the irritable bowel syndrome. Gastroenterology 1977; 72: 383-7.

2 Connell AM. The motility of the pelvic colon. II. Paradoxical motility in diarrhoea and constipation. Gut 1962; 3: 342-8.

3 Whitehead WE, Engel BT, Schuster MM. Irritable bowel syndrome: physiological and psychological differences between diarrhea predominant and constipation predominant patients. Dig Dis Sci 1980; 25: 404-13.

4 Whorwell PJ, Clouter C, Smith CL. Oesophageal motility in the irritable bowel syndrome. $\mathrm{Br} \mathrm{Med} \mathrm{J}$ 1981; 1: 1101-3.

5 Horowitz L, Farrar JT. Intraluminal small intestinal pressures in normal patients and in patients with functional gastrointestinal disorders. Gastroenterology 1962; 42: 455-64.

6 Corbett CL, Thomas S, Read NW, Hobson N, Bergman I, Holdsworth CD. Electrochemical detector for breath hydrogen determination: measurement of small bowel transit time in normal subjects and patients with the irritable bowel syndrome. Gut 1981; 22: 836-40.

7 Read NW and Al-Janabi MN. Small bowel intubation delays gastric emptying, but accelerates small bowel transit time. Gut 1982; 23: A443.

8 Almy PT, Fielding JF. The GI tract in stress and psychosocial disorder. Clin Gastroenterology 1977; 6: 3.

9 Chaudhury NA, Truelove SC. The irritable colon syndrome. $Q J$ Med 1962; 31: 307-22.

10 Read NW, Miles CA, Fisher D et al. Transit of a meal through the stomach, small intestine and colon in normal subjects and its role in the pathogenesis of diarrhea. Gastroenterology 1980; 79: 1276-82.

11 Ostick DG, Green G, Howe K et al. Simple clinical method of measuring gastric emptying of solid meals. Gut 1976; 17: 189-91.

12 Bond $\mathrm{JH}$, Levitt MD. Investigation of small bowel transit time in man using pulmonary hydrogen $\left(\mathrm{H}_{2}\right)$ measurements. J Lab Clin Med 1974; 85: 546-59.

13 Metz G, Gassull MA, Leeds AR et al. A simple method of measuring breath hydrogen in carbohydrate malabsorption by end-expiratory sampling. Clin Sci Mol Med 1976; 50: 237-40.

14 Bergman I, Coleman JE, Evans D. A simple gas chromatograph with an electrochemical detector for the measurement of hydrogen and carbon monoxide in the parts per million range, applied to exhaled air. Chromatographia 1975; 8: 581-3.

15 Hinton JM, Lennard-Jones JE, Young AC. A new method for studying gut transit times using radioopaque markers. Gut 1969; 10: 842-7.

16 Ritchie J. Pain from distension of the pelvic colon by inflating a balloon in the irritable colon syndrome. Gut 1973; 14: 125-32.

17 Flynn M, Hammond P, Darby C, Hyland J, Taylor I. 
Faecal bile acids and the irritable bowel syndrome. Digestion 1981; 22: 144-9.

18 Ingram PW. Evans G. Right iliac fossa pain in young women. Br Med J 1965; 2: 149-51.

19 Creed F. Life events and appendicectomy. Lancet 1981; 1: 1381-5.

20 Swarbrick ET. Hegarty JE, Bat L et al. Site of pain from the irritable bowel. Lancet 1980; 2: 443-6.

21 Esler MD. Goulston KT. Levels of anxiety in colonic disorders. $N$ Engl J Med 1973; 288: 16-20.
22 Almy TP, Kern F, Tulin M. Alterations in colonic function in man under stress. Gastroenterology 1949; 12: $425-36$.

23 Cann PA, Read NW, Cammack J et al. Psychological stress and the passage of a standard meal through the stomach and small intestine in man. Gut 1983; 24: 236-40.

24 Harvey RF, Heaton KW., Pomare EW. Effects of increased dietary fibre on intestinal transit. Lancet 1973; 1: 1278-80. 